\title{
Comment on "Estimation of Net Radiation in Three Different Plant Functional Types in Korea"
}

\author{
Minseok Kang and Joon Kim* \\ Department of Atmospheric Sciences, Yonsei University, Seoul 120-749, Korea \\ (Received July 10, 2009; Accepted September 24, 2009)

\section{한국의 세 개의 다른 식생기능형태에서의 순복사 추정 논문에 대한 의견} \\ 강민석·김 준* \\ 연세대학교 대기과학과 \\ (2009년 7월 10일 접수; 2009년 9월 24일 수락)
}

Net Radiation $\left(R_{N}\right)$ is the major driving force for biophysical and biogeochemical processes in the terrestrial ecosystems, which is one of the most critical variables in both measurement and modeling. Despite its importance, there are only 10 weather stations conducting $R_{N}$ measurements among the 544 stations operated by Korea Meteorological Administration (KMA; KMA, 2008). The measurement of incoming shortwave radiation $\left(R_{S} \downarrow\right)$ is, however, conducted at 22 stations while that of sunshine duration is conducted at all the manned stations. In this context, the recent research for estimating $R_{N}$ using $R_{S} \downarrow$ in Korean peninsula by Kwon (2009) is of great worth. The author used a linear regression and the radiation balance methods. We generally agree with the author that, in terms of simplicity and practicality, both methods show reliable applicability for estimating $R_{N}$. We noted, however, that the author's experimental method and analysis need some clarification and improvement, that are addressed in the following perspectives: (1) the use of daily integrated data for regression, (2) the use of measured albedo, (3) the use of linear coefficients for whole year data, (4) methodological improvement, (5) the use of sunshine duration, and (6) the error assessment.

\section{THE USE OF DAILY INTEGRATED DATA FOR THE REGRESSION}

The regression coefficients, $a$ and $b$, in the linear regression equation of Kwon (2009) (i.e., $R_{N}=a R_{s} \downarrow$ $+\mathrm{b}$ ) represent 1- $\alpha$ (which determines the amount of net shortwave radiation, $R_{S N}$; where $\alpha$ is albedo) and net longwave radiation $\left(R_{L N}\right)$, respectively. The physical meaning of these coefficients makes sense only when the data with shorter time scale (e.g., 30 minute, 1 hour, or at least daytime and nighttime separately) are used in the regression. Instead, for simplicity, Kwon (2009) used daily-integrated data. It should be noted that the physical parameters (i.e., $\alpha$ and $R_{L N}$ ) obtained by using the daily-integrated data are quite different from those obtained from the direct measurements. Table 1 shows that the parameters estimated from the regression with $30 \mathrm{~min}$. data not only make better sense in terms of their physical meaning, but also compare better with those obtained from the direct observation than those estimated from the regression with daily-integrated data.

In Table 1 , the coefficient, $b$ (i.e., $R_{L N}$ ), deserves further consideration. As pointed out by Kwon (2009), the contribution of changes in $R_{L}$ with changing weather conditions is not negligible in estimating $R_{N}$. In order to

* Corresponding Author : Joon Kim (joon-kim@yonsei.ac.kr) 
Table 1. The seasonal and annual averages of $1-\alpha$ and $R_{L N}$ from the measurements and the regression analysis using for Gwangneung deciduous forest in 2008

\begin{tabular}{|c|c|c|c|c|c|c|}
\hline \multirow{3}{*}{ Period } & \multicolumn{3}{|c|}{$a(=1-\alpha)$} & \multicolumn{3}{|c|}{$\bar{c} b\left(=R_{L N}\right.$ in $\left.\mathrm{MJ} \mathrm{m}^{-2}\right)$} \\
\hline & \multirow{2}{*}{$\begin{array}{c}\text { Observed } \\
\text { Data }\end{array}$} & \multicolumn{2}{|c|}{ Regression } & \multirow{2}{*}{$\begin{array}{c}\text { Observed } \\
\text { Data }\end{array}$} & \multicolumn{2}{|c|}{ Regression } \\
\hline & & $30 \mathrm{~min}$. & Daily & & $30 \mathrm{~min}$. & Daily \\
\hline Winter & 0.91 & 0.83 & 0.43 & -6.3 & -5.4 & -1.9 \\
\hline Spring & 0.88 & 0.83 & 0.61 & -5.3 & -4.4 & -0.8 \\
\hline Summer & 0.90 & 0.84 & 0.65 & -3.4 & -2.4 & -0.5 \\
\hline Fall & 0.92 & 0.85 & 0.65 & -5.8 & -4.8 & -2.7 \\
\hline Annual & 0.90 & 0.84 & 0.70 & -5.2 & -4.3 & -2.6 \\
\hline
\end{tabular}

Table 2. The regression coefficients ( $a$ and $b$ ) of for the Gwangneung deciduous forest in 2008 using all the data, only the data under cloudy conditions $\left(R_{S} \downarrow / R_{S 0}<0.5\right)$, and under clear conditions $\left(R_{S} \downarrow / R_{S 0} \geq 0.5\right)$

\begin{tabular}{|c|c|c|c|c|c|c|}
\hline \multirow{2}{*}{ Period } & \multicolumn{3}{|c|}{$a$} & \multicolumn{3}{|c|}{$b\left(=R_{L N}\right.$ in $\left.\mathrm{MJ} \mathrm{m}^{-2}\right)$} \\
\hline & All & Cloudy & Clear & All & Cloudy & Clear \\
\hline Winter & 0.83 & 0.86 & 0.84 & -5.4 & -3.0 & -6.4 \\
\hline Spring & 0.83 & 0.85 & 0.84 & -4.4 & -2.5 & -5.6 \\
\hline Summer & 0.84 & 0.86 & 0.86 & -2.4 & -1.1 & -3.9 \\
\hline Fall & 0.85 & 0.86 & 0.86 & -4.8 & -2.2 & -5.2 \\
\hline Annual & 0.84 & 0.86 & 0.86 & -4.3 & -2.1 & -5.6 \\
\hline
\end{tabular}

take the influence of changing $R_{L}$ into account, we suggest that the data may be divided into clear and cloudy conditions based on clearness index, i.e. relative shortwave radiation ( $=R_{S} \downarrow / R_{S 0}$, where $R_{S 0}$ is clear-sky solar radiation) (e.g., Allen et al., 1998). For example, at the Gwangneung deciduous forest, $R_{L N}$ on clear days is typically 2-3 times larger than $R_{L N}$ on cloudy days (Table 2).

\section{THE USE OF THE MEASURED ALBEDO}

As an alternative method to estimate $R_{N}$, Kwon (2009) has also proposed to use the surface radiation balance equation. In this approach, all the terms (except $R_{S} \downarrow$ ) should be approximated based on a look-up table or empirical relationships using the readily available and measurable parameters unless they are known $a$ priori. Nevertheless, Kwon (2009) used the albedo values observed directly at the study sites probably in order for an accurate assessment of the radiation balance method. In reality, the direct observation of $\alpha$ is rarely available. For more general application and assessment of the method, indirect values of $\alpha$ should be used, that are derived from (1) the literature, (2) climatological values for the site (or plant functional type)
Table 3. The climatology (i.e., monthly averages) of albedo $(\alpha)$ for three plant functional types: deciduous forest (Gwangneung: 2006-2008), coniferous forest (Gwangneung: 20072008), and cropland (Haenam: 2004, 2006, 2008)

\begin{tabular}{lccc}
\hline \hline & \multicolumn{3}{c}{ Albedo $(\alpha)$} \\
\cline { 2 - 4 } & $\begin{array}{c}\text { Deciduous } \\
\text { Forest }\end{array}$ & $\begin{array}{c}\text { Coniferous } \\
\text { Forest }\end{array}$ & Cropland \\
\hline January & 0.09 & 0.05 & 0.24 \\
February & 0.08 & 0.05 & 0.23 \\
March & 0.07 & 0.04 & 0.22 \\
April & 0.08 & 0.05 & 0.20 \\
May & 0.12 & 0.05 & 0.18 \\
June & 0.11 & 0.05 & 0.16 \\
July & 0.08 & 0.03 & 0.18 \\
August & 0.07 & 0.03 & 0.19 \\
September & 0.07 & 0.03 & 0.19 \\
October & 0.08 & 0.04 & 0.21 \\
November & 0.07 & 0.05 & 0.22 \\
December & 0.07 & 0.05 & 0.24 \\
\hline
\end{tabular}

of interest, or (3) $\alpha$ calculated from the linear regression coefficient, $a(=1-\alpha)$. In Table 3 , based on the multi-years of field observation in the KoFlux database (www.koflux.org), we have provided the climatology of $\alpha$ (i.e., monthly averages) reported for the three plant functional types: Gwangneung deciduous forest 


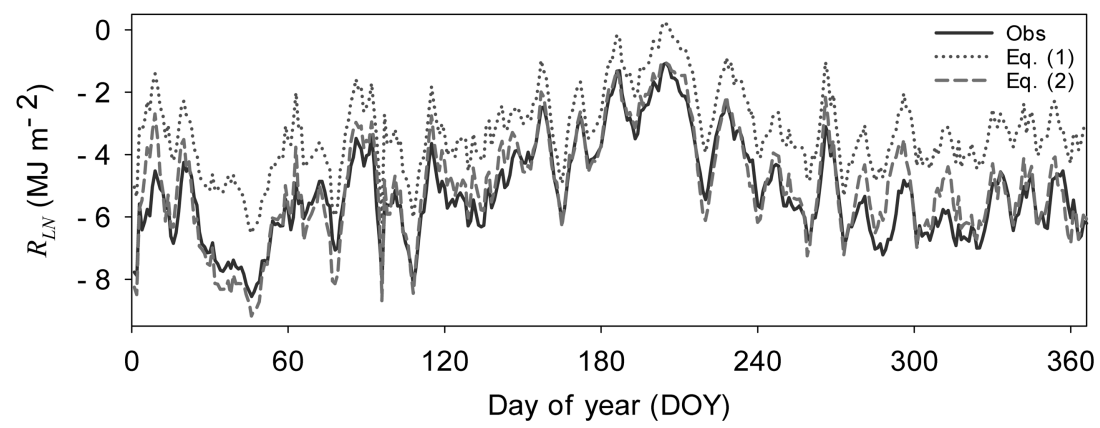

Fig. 1. Comparison of the observed $R_{L N}(\mathrm{Obs})$ with the estimated $R_{L N}$ using Eq. (1) and Eq. (2) for the Gwangneung deciduous forest in 2008.

(2006 2008), Gwangneung coniferous forest (2007 2008), and Haenam cropland (2004, 2006, 2008). These albedo values are somewhat smaller than those generally reported for deciduous $(0.15 \sim 0.25)$ and coniferous forest $(0.1 \sim 0.15)$, and comparable to those for croplands (short green vegetation: $0.1 \sim 0.2$, dry vegetation: $0.2 \sim$ 0.3) (e.g., Hartman, 1994).

\section{THE USE OF LINEAR COEFFICIENTS FOR WHOLE YEAR DATA}

Kwon (2009) correctly acknowledged that the linear coefficients from the regression method showed significant seasonal changes. In the assessment of the errors in the linear regression method, however, the author did not take such seasonality into consideration. Instead, the regression coefficients for an entire year's data were examined, which resulted in an overestimation of the coefficients during the winter for all three plant functional types. We come back to this issue of error assessment later.

\section{METHODLOGICAL IMPROVEMENT}

Kwon (2009) used the estimation equation for $R_{L N}$ proposed by Allen et al. (1998):

$R_{L N}=-\sigma\left[\frac{T_{\max }^{4}+T_{\min }^{4}}{2}\right]\left(0.34-0.14 \sqrt{e_{a}}\right)\left(1.35 \frac{R_{s} \downarrow}{R_{s 0}}-0.35\right)$

where $\sigma$ is the Stefan-Boltzmann constant $\left(=4.903 \cdot 10^{-9}\right.$ $\mathrm{MJ} \mathrm{K}^{-4} \mathrm{~m}^{-2}$ day $\left.^{-1}\right), T_{\max }$ and $T_{\min }$ are the maximum and minimum air temperatures $(\mathrm{K}), e_{a}$ is actual vapor pres- sure ( $\mathrm{kPa}), R_{S 0}$ is clear-sky solar radiation. Eq. (1) is based on Brunt (1939)'s expression that consists of the Stefan-Boltzmann equation and the empirical terms (specified for cropland) to describe effects of air humidity and cloudiness. We note that there is a similar type of equation, the formula of Monteith (1961) that is also known to show good agreement between the estimated and the observed:

$$
\begin{aligned}
& R_{L N}=-\left[\sigma T^{4}(0.47-0.065 \sqrt{e})+\Delta R_{L}\right][0.1+0.9 s] \\
& \Delta R_{L}=\sigma T_{0}^{4}-\sigma T^{4}
\end{aligned}
$$

where $e$ is mean vapor pressure (hPa), $T_{0}$ and $T$ are the mean surface and air temperatures $(\mathrm{K}), s$ is relative sunshine duration which is observed sunshine duration over clear-sky sunshine duration. Fig. 1 shows the comparison between the $R_{L N}$ calculated by Eq. (1) and those by Eq. (2) against the observed $R_{L N}$ at the Gwangneung deciduous forest. Noticeably for the entire year, Eq. (2) outperformed Eq. (1) in reproducing the observed $R_{L N}$.

\section{THE USE OF SUNSHINE DURATION}

In Korea, sunshine duration is observed by Automated Surface Observing System (ASOS) at all 84 manned stations (with an average distance between the stations being $36 \mathrm{~km}$ ). If it is possible to use those sunshine duration data for the estimation of $R_{S} \downarrow$, then the methods proposed by Kwon (2009) can be readily extended to produce the map of $R_{N}$ for the entire Korean Peninsula. In fact, we found that there is a strong correlation between the relative shortwave radiation $\left(R_{S} \downarrow / R_{S 0}\right)$ and the relative sunshine duration $(s)$ at 

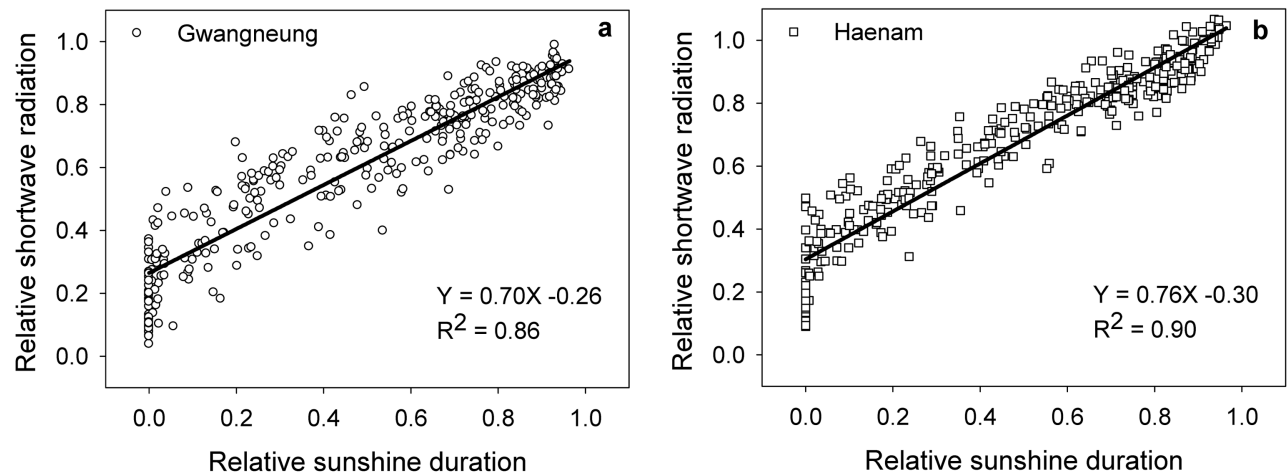

Fig. 2. Linear regressions between relative shortwave radiation $\left(R_{S} \downarrow / R_{S 0}\right)$ and relative sunshine duration ( $s$ ) at (a) the Gwangneung site and (b) the Haenam site in 2008. (For Gwangneung, the sunshine duration at the Dongdoocheon weather station was used, which is about $20 \mathrm{~km}$ apart.)

Table 4. Errors in the estimation of $R_{N}$ at the Gwangneung deciduous forest by using the linear regression method (LRM1), the linear regression method with clearness index (LRM2), and the radiation balance method with Eq. (2) (RBM). MBE, RMSE, and $d$ indicate mean bias error, root mean square error, and index of agreement, respectively. The results are provided for the estimated $R_{N}$ using the observed $R_{S} \downarrow$ and the estimated $R_{S} \downarrow$ using the relative sunshine duration $(s)$

\begin{tabular}{cccccccc}
\hline \hline \multirow{2}{*}{$\begin{array}{c}\text { Statistical } \\
\text { index }\end{array}$} & \multicolumn{3}{c}{ Observed $R_{S} \downarrow$} & & \multicolumn{3}{c}{ Estimated $R_{S} \downarrow$ with $s$} \\
\cline { 2 - 4 } \cline { 6 - 8 } & LRM1 & LRM2 & RBM & & LRM1 & LRM2 & RBM \\
\hline MBE & -0.24 & 0.02 & 0.53 & & -0.69 & -0.44 & 0.04 \\
RMSE & 2.11 & 1.53 & 1.44 & & 2.69 & 2.59 & 2.03 \\
$d$ & 0.96 & 0.98 & 0.98 & & 0.92 & 0.92 & 0.94 \\
\hline
\end{tabular}

the Gwangneung and Haenam sites in 2008 (Fig. 2). The seasonal and inter-annual variations of the regression coefficients were insignificant, suggesting the possibility of using sunshine duration for the $R_{S} \downarrow$ estimation. It should be noted that the regression coefficients were different between the Gwangneung and the Haenam sites, requiring further analysis on these site-specific features that may be associated with fac- tors such as instrument bias, separation between sunshine recorder and pyranometer.

\section{THE ERROR ASSESSMENT}

Finally, using the KoFlux database for the Gwangneung deciduous forest in 2007, we performed the seasonal error assessment of the proposed methods: the

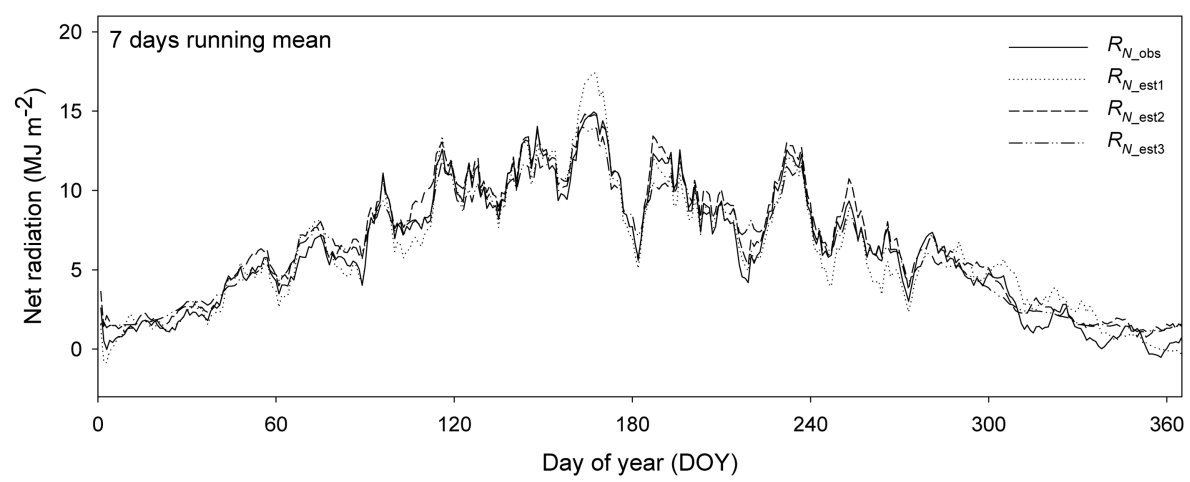

Fig. 3. Comparison of the estimated net radiation from the linear regression method $\left(R_{N_{-} \text {est } 1}\right)$, the radiation balance method using Eq. (2) $\left(R_{N_{-} \text {est2 }}\right)$, and the sunshine duration $\left(R_{N_{-} \text {est3 }}\right)$ against the observed net radiation $\left(R_{N_{-} \text {obs }}\right)$ at the Gwangneung deciduous forest in 2007 . 
linear regression method (LRM1), the linear regression method with clearness index (LRM2), and the radiation balance method with Eq. (2) (RBM). Following Kwon (2009), the results are presented in Table 4 in terms of mean bias error (MBE), root mean square error (RMSE), and index of agreement $(d)$. Each method showed good agreement with the observation with $d>$ 0.95. In comparison with the results of Kwon (2009), the revised methods show an improvement. Furthermore, the use of the sunshine duration has proved a promising tool to produce acceptable estimates of $R_{N}$ (with $d>0.9$ ) for large-scale mapping, for instance (Table 4 and Fig. 3).

\section{ACKNOWLEGMENT}

This study is supported by a grant (Code: 1-8-3) from Sustainable Water Resources Research Center of $21^{\text {st }}$ Century Frontier Research Program, the Long-term Ecological Study and Monitoring of Forest Ecosystem Project of Korea Forest Research Institute, the A3 Foresight Program from the Korea Science and Engi- neering Foundation, and Korea Meteorological Administration.

\section{REFERENCES}

Allen, R.G., L. S. Pereira, D. Raes, M. Smith, 1998: Crop Evapotranspiration: Guidelines for Computing Crop Requirements, Irrigation and Drainage Paper, 56 Food and Agriculture Organization Of the United Nation, Rome.

Brunt, D., 1939: Physical and Dynamical Meteorology. Cambridge University Press.

Hartmann, D. L., 1994: Global Physical Climatology. Academic Press. 411pp.

Korea Meteorological Administration, 2008: Annual climatological report. 302pp.

Kwon, H., 2009: Estimation of net radiation in three different plant functional types in Korea. Korean Journal of Agricultural and Forest Meteorology 11, 79-85.

Monteith, J. L., 1961: An Empirical Method for Estimating Net Long-Wave Radiation Exchanges over the British Isles. Quarterly Journal of Royal Meteorological Society 87 171-179. 